that with the additional cost of producing more anti-D immunoglobulin about $£ 200000$ would have to be spent for each baby saved. Tovey also pointed out that the immunoglobulin must be obtained by plasmapheresis of donors injected with Rh-positive cells and that this procedure is not without risk. Moreover, about $25 \%$ of mothers given anti-D immunoglobulin develop antiglobulins, and these might possibly prove to be a long-term hazard to both mother and infant. Tovey's survey also showed that in about half the cases in the 1978 survey sensitisation was due to a failure to administer anti-D at the end of the previous pregnancy, usually the result of human error. Since only about one-fifth of the sensitisation found in Britain in 1978 occurred in primigravidae a far greater reduction in mortality could be achieved by ensuring that all $\mathrm{Rh}$-negative mothers receive anti-D immunoglobulin postnatally.

The extra money required for antenatal treatment would be sufficient to enable another 360 patients with end-stage renal failure to have a renal transplant. Quite reasonably, Tovey concluded that "in a world in which more consideration must be given to the cost-effectiveness of health care, it might be wiser to accept that the total elimination of $\mathrm{Rh}$ sensitisation is beyond our economic grasp."

${ }^{1}$ Diamond LK. Erythroblastosis foetalis or haemolytic disease of the newborn. Proc $R$ Soc Med 1974;40:546-50.

2 Shapiro M. Safer exchange transfusion with citrated blood. In : Holländer $\mathrm{L}$, ed. Proceedings of the International Society of Blood Transfusion. 10th Congress. Stockholm. 1964. Basle: Karger, 1965.

${ }^{3}$ Finn R, Clarke CA, Donohoe WTA, et al. Experimental studies on the prevention of $\mathrm{Rh}$ haemolytic disease. ABO incompatibility. $\mathrm{Br}$ Med $\mathcal{f}$ $1961 ; 1: 1486-90$

4 Freda VJ, Gorman JG. Antepartum management of Rh haemolytic disease. Bulletin of the Sloane Hospital for Women 1962;8:147-58.

${ }^{5}$ Davey MG, Zipursky A. McMaster conference on prevention of Rh immunization. 1977. Vox Sang 1979;36:50-7.

6 Tovey GH. Should anti-D immunoglobulin be given antenatally ? Lancet 1980 ;ii :466-8.

\section{Infective endocarditis}

Infective endocarditis remains one of the few life-threatening fevers. Horder's classic description ${ }^{1}$ of the disease in 1909 set the scene until the antibiotic era, and the changes that resulted have encouraged physicians to make periodic surveys of the condition. ${ }^{2-7}$ The task is not difficult, for the number of patients is not overwhelming, and in most cases a specific diagnosis is provided by the bacteriologist; each, moreover, is a therapeutic challenge and the outcome is usually soon apparent. The use of antibiotics, the decline in acute rheumatic fever, the increased survival of patients operated on for congenital heart disease, the increase in the elderly population, and the abuse of drugs by intravenous injections have all contributed to the changing picture, which formed the subject of Hayward's 1973 Croonian lecture. ${ }^{\times}$

The recent pattern in Britain has been shown by four reports. The first ${ }^{9}$ concerned 78 patients in south-east Scotland seen between 1969 and 1972. Some 23 infections occurred in patients with rheumatic valve disease, 16 in non-rheumatic aortic valve disease, 13 on valve prostheses, and 19 in hearts previously presumed to be normal. Streptococcus viridans was the most common organism, followed by non-hacmolytic streptococci and then Staphylococcus aureus. Almost half the patients died, with cardiac failure and emboli accounting for two-thirds of these deaths. The annual incidence was 16 cases per million population. Secondly, 70 patients were seen in the
West Midlands region, ${ }^{10}$ where almost a half of infections were caused by Str viridans, a quarter by staphylococci, a tenth by enterococci, and the remainder by rarer organisms. Rheumatic heart disease was a predisposing factor in less than a quarter of patients, and in 31 of the 70 there was no obvious pre-existing abnormality; 24 patients died. At St Bartholomew's Hospital, London, ${ }^{11} 60$ patients with endocarditis were seen between 1966 and 1975. Of these, 21 had rheumatic heart disease, 13 congenital heart disease, and in 18 there was no previous underlying lesion. Streptococci were the commonest organisms (41 patients, with Str viridans in 31). At six months a fifth of the patients had died. The fourth report, from St Thomas's Hospital, London, covers the years $1970-9^{12}$ : in 88 patients with endocarditis proved by blood culture (culture-negative ones were excluded) streptococci were responsible in twothirds and staphylococci in a quarter. The aortic valve was affected in 22 cases, the mitral in 22 , and prosthetic valves in 19. Apparently normal valves were affected in 24 episodes, rheumatic valves in 18, and "degenerate" valves in 23 . Just over a third of the patients died.

The common features on presentation remain the classical ones: a murmur, fever, cardiac failure, embolism, enlargement of the spleen, and anaemia. ${ }^{10}$ On suspicion of the disease the first diagnostic step should be to draw blood for cultures. The high chances of a rapid and successful identification of the organism have long been known. ${ }^{13}$ Werner and colleagues ${ }^{14}$ reported that in 206 cases of bacterial endocarditis with positive cultures $95 \%$ of 789 cultures grew the responsible organism. In streptococcal disease the first culture was positive in $96 \%$ of cases, and one of the first two cultures in $98 \%$. To clinch the diagnosis by weight of evidence blood is customarily obtained by at least three separate venepunctures, within 24 hours if there is no clinical urgency, but within a few hours if the patient is acutely ill. The previous administration of antibiotics will reduce the chances of a positive culture, though this problem may have been exaggerated in the past. ${ }^{10} 12$

Endocarditis remains, then, a prevalent disease with a substantial mortality. The male to female ratio is about $1 \cdot 5: 1$. Streptococci, overwhelmingly the dominant organisms at the start of the antibiotic era, ${ }^{2}$ remain the most frequent, but the proportion of staphylococcal infections has increased in all age groups, ${ }^{12}$ when the disease is often acute with a high mortality. Fungal infections, usually in patients after operation or drug abusers, are less common but dangerous and almost always require surgical eradication..$^{15} \mathrm{~A}$ host of rarer organisms has been reported in the mass of papers on the disease. Culturenegative infections ${ }^{16}$ form a difficult minority. The mean age of affected patients is rising, and so is the proportion without previously recognised valve disease. The overall mortality is still $20 \%$ to $40 \%$ despite antibiotics and surgery, and in a series of 48 patients with prosthetic valve infection no fewer than 33 died. ${ }^{17}$ Prophylaxis remains of the highest importance, especially in dental surgery, ${ }^{18} 19$ but can never eradicate the disease. Prompt diagnosis and early treatment give the patient the best chance of survival. A useful summary of current antibiotic treatment has recently been published in Prescribers' Fournal. ${ }^{20}$

${ }^{1}$ Horder TJ. Infective endocarditis with an analysis of 150 cases with special reference to the chronic form of the disease. $Q \mathcal{F} M e d 1909 ; 2: 289-324$

2 Cates JE, Christie RV. Subacute bacterial endocarditis: a review of 442 patients treated in 14 centres appointed by the Penicillin Trials Committee of the Medical Research Council. Qf Med 1951;20:93-130.

${ }^{3}$ Lerner PI, Weinstein L. Infective endocarditis in the antibiotic era. N Engl 7 Med 1966;274:199-206, 259-66, 323-31, 388-93.

${ }^{4}$ Hughes P, Gauld WR. Bacterial endocarditis: a changing disease. $Q \mathcal{F}$ Med $1966 ; 35: 511-20$.

${ }^{5}$ Shinebourne EA, Cripps CM, Hayward GW, Shooter RA. Bacterial 
endocarditis 1956-1965: analysis of clinical features and treatment in relation to prognosis and mortality. Br Heart $\mathcal{f} 1969 ; 32: 536-42$

${ }^{6}$ Cherubin CE, Neu HC. Infective endocarditis at the Presbyterian Hospital in New York City from 1938-1967. Am f Med 1971 ;51:83-96.

${ }^{7}$ Kaye D. Changes in the spectrum, diagnosis and management of bacterial and fungal endocarditis. Med Clin North Am 1973;57(4):941-57.

${ }^{8}$ Hayward GW. Infective endocarditis: a changing disease-I, II. Br MedF 1973 ;ii :706-9, 764-6.

9 Smith RH, Radford DJ, Clark RA, Julian DG. Infective endocarditis; a survey of cases in the south-east region of Scotland 1969-72. Thorax 1976;31 :373-9.

10 Schnurr LP, Ball AP, Geddes AM, Gray J, McGhie D. Bacterial endocarditis in England in the 1970 s: a review of 70 patients. $Q \mathcal{F}$ Med 1977; $46: 499-512$.

${ }^{11}$ Lowes JA, Hamer J, Williams G, et al. 10 years of infective endocarditis at St Bartholomew's Hospital : analysis of clinical features and treatment in relation to prognosis and mortality. Lancet $1980 ; \mathrm{i}: 133-6$.

${ }^{12}$ Moulsdale MT, Eykyn SJ, Phillips I. Infective endocarditis, 1970-1979. A study of culture-positive cases in St Thomas's Hospital. $Q \mathcal{F ~ M e d}$ $1980 ; 49: 315-28$

13 Belli J, Waisbren BA. The number of blood cultures necessary to diagnose most cases of bacterial endocarditis. Am F Med Sci 1956;232:284-8.

14 Werner AS, Cobbs C, Kaye D, Hook EW. Studies on the bacteremia of bacterial endocarditis. FAMA $1967 ; 202: 199-203$.

15 Turnier E, Kay JH, Bernstein S, Mendez AM, Zabiate P. Surgical treatment of candida endocarditis. Chest $1975 ; 67: 262-8$.

16 Pesanti EL, Smith IM. Infective endocarditis with negative blood cultures. Am f Med 1979;66:43-50.

17 Masur H, Johnson WD. Prosthetic valve endocarditis. $\mathcal{F}$ Thorac Cardiovasc Surg 1980;80:31-7.

18 Durack DT. Current practice in prevention of bacterial endocarditis. Br Heart $\mathcal{f} 1975 ; 37: 478-81$.

19 Kaplan EL, Anthony BF, Bisno A, et al. Prevention of bacterial endocarditis. Circulation 1977;56:139A-43A.

${ }^{20}$ Oakley CM, Darrell JH. Infective endocarditis. Prescribers' fournal 1980; 20:98-106.

\section{Bakers' asthma}

Interest in occupational asthma has been rekindled in recent years by the description of important new causes such as isocyanates, solder fluxes, and biological washing powders. ${ }^{1}$ Moreover, investigative techniques have been refined, and simpler methods of assessing the efficacy of treatment have been developed, leading to the possibilities that occupational asthma might become a scheduled occupational disease in Britain and that sufferers might receive industrial disablement benefit.

Of the multitude of known causes of occupational asthma, exposure to grains and flour is the one with the longest history and may also be the most common. Roman bakers are known to have worn masks to protect them from the flour, and Ramazzini, the father of occupational medicine, described shortness of breath and urticaria in grain workers. ${ }^{2}$ In the 1930s the allergic basis of such symptoms in millers was shown,${ }^{3}$ while in the 1940s grain and flour dust were recognised to contain many potential allergens from the flour itself to wheat hairs, fungi, and even mites. ${ }^{4}$ Curiously, more recent work has rediscovered the importance of mites in provoking asthma in farmers handling grains. ${ }^{5}$

There are no reliable estimates of the prevalence of asthma among bakers in Britain. Nevertheless, studies in the Federal Republic of Germany have given us some idea of the pattern of sensitisation and of the numbers of people who might claim industrial disablement benefit for bakers' asthma. Herxheimer $^{6}{ }^{7}$ skin tested all bakers' apprentices in West Berlin and found a progressive increase in the number who showed sensitivity to flour up to over $20 \%$ by the fifth year of apprenticeship. Seven per cent developed skin, nasal, or bronchial symptoms, though very few regarded these as more than a nuisance. A more recent study ${ }^{8}$ found symptoms in almost $5 \%$ of apprentices and about $20 \%$ of established bakers - though some of these had taken as long as 32 years to develop symptoms. All these men had rhinitis and most had asthma as well. This study also showed an increasing frequency of positive bronchial provocation tests with acetylcholine with greater length of exposure to flour, suggesting that increased bronchial reactivity may just as well be the result of sensitisation to flour as its cause.

Extrapolation from these figures suggests that there are large numbers of bakers presenting to their doctors with workrelated allergic symptoms. Each year in West Germany about 300 bakers claim industrial injury compensation and about a quarter of these receive it. ${ }^{8}$ In Britain clinical impressions suggest that bakers' asthma is not as common as the German figures imply. Possibly young men leave the trade if they develop troublesome symptoms early, leaving a relatively resistant population. Furthermore, much British baking is carried out by large companies, where control of dust levels is generally good, perhaps reducing sensitisation to a minimum. The addition of occupational asthma to the list of scheduled diseases will allow better estimates to be made of the size of the problem.

Even when bakers become eligible for industrial benefit, however, most will prefer to remain in their trade if their symptoms can be controlled. Prevention of exposureprimarily by reduction of dust levels but also by suitable respirators-remains the cornerstone of management. Occupational asthma also usually responds satisfactorily to standard treatment. Regular inhalation of cromoglycate or beclomethasone, supplemented by a beta-adrenergic aerosol, is usually sufficient to maintain the patient in reasonable health. ${ }^{8}{ }^{9}$ Rhinitis, too, often responds to regular prophylaxis with cromoglycate solution. An appropriate combination of environmental and pharmacological measures should be adequate to keep most victims of bakers' asthma well and at work; and disablement benefit should soon be available to those unfortunate enough not to respond to these measures.

${ }^{1}$ Anonymous. Occupational asthma. $\mathrm{Br}$ Med $\mathcal{f} 1979$;ii :82.

2 Ramazzini B. De morbis artificum diatriba. 1700. Cave W, transl. Chicago: Wright, 1940.

${ }^{3}$ Duke WW. Wheat hairs and dust as a common cause of asthma among workers in wheat flour mills. $7 A M A 1935 ; 105: 957-8$.

4 Jimenez-Diaz C, Lahoz C, Canto G. The allergens of mill dust. Asthma in millers, farmers, and others. Ann Allergy 1947;5:519-25.

${ }^{5}$ Ingram CG, Jeffrey IG, Symington IS, Cuthbert OD. Bronchial provocation studies in farmers allergic to storage mites. Lancet 1979; ;i:1330-2.

${ }^{6}$ Herxheimer H. Skin sensitivity to flour in bakers' apprentices. Lancet $1967 ; \mathrm{i}: 83-4$.

${ }^{7}$ Herxheimer $\mathrm{H}$. The skin sensitivity to flour of bakers' apprentices. A final report of a long term investigation. Acta Allergologica 1973;28:42-9.

8 Thiel H, Ulmer WT. Bakers' asthma: development and possibility of treatment. Chest $1980 ; 78$, suppl:400-5.

${ }^{9}$ Hendrick DJ, Davies RJ, Pepys J. Bakers' asthma. Clin Allergy 1976;6: 241-50.

\section{Correction}

\section{Management of alcohol withdrawal symptoms}

We regret that in the fourth paragraph of our leading article on the management of alcohol withdrawal symptoms (14 February, p 502) the dosage of chlormethiazole was wrongly given as $500-1500 \mathrm{~g}$ every six hours. This should have read $500-1500 \mathrm{mg}$ every six hours. 